УДК 621.744

И.А. Гримзин

Национальный технический университет

«Харьковский политехнический институт»,

г. Харьков, Украина

\title{
ПОВЫШЕНИЕ КАЧЕСТВА ПЕСЧАНО-ГИПСОВЫХ ФОРМ И СТЕРЖНЕЙ
}

\section{I.A. Grimzin}

National Technical University "Kharkiv

Polytechnical Institute", Kharkiv, Ukraine

\section{IMPROVING THE QUALITY OF SANDY-GYPSUM FORM AND ROD}

Цель. Целью работы является повышение качества песчано-гипсовых форм за счет интенсификации прочесса их сушки, позволяющая сократить время ее проведения и получать точные отливки сложной формы необходимого качества.

Методика. Исследование проводилась на иилиндриеских образиах из песчаной смеси на основе гипса в качестве связующего материала. Образиы подвергались сушке в микроволновой печи «Хот-Стрим» ДВ-6-02-6-100. Взвешиванием определялось потеря влажности образиами в зависимости от времени сушки образиов.

Результаты. Изучен прочесс потери влаги образиами и разработаны математические зависимости потери влаги от продолжительности сушки. Определено необходимое количество воды, что позволяет снизить брак по газовым раковинам и улучшить качество поверхности отливки. Экономический эффект при внедрении новой технологии сушки с использованием микроволновой вакуумной установки позволил практически вдвое сократить затраты на электричество.

Научная новизна. Впервые научно-обоснован режим работы микроволновой печи для сушки песчаногипсовых форм и стержней. Разработаны математические зависимости потери влаги образиами в зависимости от продолжительности сушки, которые можно описать в виде экспоненииальных зависимостей.

Практическая ценность. Разработан технологический процесс сушки форм с использованием микроволновой установки, позволивший повысить качество форм и стержней за счет стабилизации их размеров, а также качество сложных алюминиевых отливок за счет снижения брака по газовым раковинам, .

Предложенный режим сушки позволяет снизить длительность сушки на $40 . .50 \%$ и тем самым уменьшить затраты на электроэнергию до $50 \ldots 70 \%$ в зависимости от размеров стержня.

Ключевые слова: формовочные смеси на основе гипса, сушка, микроволновая установка, алюминиевые отливки.

DOI: $10.34185 / 0543-5749.2019-5-6-12-17$

Анализ литературных данных и постановка проблемы. Освоение производства современных приборов, механизмов и машин, повышение их экономичности, надежности и долговечности во многом зависит от технологии производства литых деталей.

В настоящее время в мелкосерийном и опытном производстве применяется технология литья цветных металлов в песчано-гипсовые формы. Область применения литья в такие формы весьма разнообразна. Эго изготовление сложных отливок из цветных сплавов различной конфигурации: корпусные детали, турбинные колеса со сложными лопатками и т.п., художественное литье [1 - 7].

Преимуществами данного вида литья является: получение отливок с чистой поверхностью и высокой точностью, соизмеримыми с отливками, полученными литьем по выплавляемым моделям и литьем под давлением; простота

(С Гримзин И.А., 2019 
технологического процесса получения отливки по модели, изготовленной из различных материалов (дерево, пластмасса, пластилин, любой металл и др.); малая теплопроводность форм и их достаточная прочность, что обеспечивает спокойное заполнение металлом сложных и тонкостенных отливок.

Кроме того такая технология позволяет получать отливки разных размеров от мелких до крупных, различного веса от нескольких граммов до десятков килограмм [2-4, 8-10].

Для для изготовления песчано-гипсовых смесей используются широко распространенные дешевые материалы - гипс, песок, асбест и т. п. Такие формовочные смеси состоят из трех главных компонентов: огнеупорного материала песка, кристобалита, шамота, маршалита; армирующего материала - различных сортов асбеста с разной длиной волокна и связки в виде гипса.

Отличительной особенностью формовочного материала на основе гипса является хорошая текучесть его в смеси с водой. Хорошая текучесть, чистота поверхностей после затвердевания и точность воспроизведения отпечатка делают возможным получение из них формы по любой сложной модели. Способность гипса быстро затвердевать, легкость и простота формовки является также важным свойством этого материала.

На свойства формы и стержней оказывает влияние концентрация в смеси гипса, воды, различных видов связующих, огнеупорных наполнителей и их гранулометрический состав, температура и продолжительность сушки форм.

Однако, на сегодня по-прежнему «узким» местом остается операция сушки форм. Сушка является энергоемкой и продолжительной операцией. Неполное просушивание даже небольших форм, изготовленных из смесей с максимальным содержанием гипса и асбеста, приводит к большим изменениям размеров форм при сушке $[4,8,9]$.

Целью работы является повышение качества песчано-гипсовых форм за счет интенсификации процесса их сушки, позволяющая сократить время ее проведения и получать точные отливки сложной формы необходимого качества.

Результаты исследований. Процессы, происходящие при нагревании формы или стержня, можно описать следующим образом [7].

В начальный период при нагревании формы на основе гипса происходит обезвоживание еe с образованием полугидрата $\mathrm{CaSO}_{4} \cdot 0,5 \mathrm{H}_{2} \mathrm{O}$ и удаление из песчано-гипсовой смеси капельно- жидкой воды. При низких температурах или недостаточной длительности нагревания формы в ее составе может содержаться некоторое количество, неразложившегося двуводного гипса. В зависимости от способа тепловой обработки происходит образование $\alpha$ - или $\beta$-модификации полуводного гипса.

Химическая реакция разложения двугидрата протекает теоретически при температуре $107^{\circ} \mathrm{C}$ :

$\mathrm{CaSO}_{4} \cdot 2 \mathrm{H}_{2} \mathrm{O}=\mathrm{CaSO}_{4} \cdot 0,5 \mathrm{H}_{2} \mathrm{O}+1,5 \mathrm{H}_{2} \mathrm{O}$.

В интервале температур $170-200{ }^{\circ} \mathrm{C}$ происходит дальнейшая потеря гипсовыми формами кристаллизационной воды. В этом интервале температур начинает образовываться, так называемый, растворимый ангидрит $\left(\mathrm{CaSO}_{4}\right)$. активно соединяющийся с водой и вновь переходящий в полугидрат. При температурах $200-$ $400{ }^{\circ} \mathrm{C}$ происходит почти полное удаление из гипса химически связанной воды и образуется смесь нерастворимого и растворимого ангидрита. Реакция гидратации проходит очень медленно. При температуре выше $400-450{ }^{\circ} \mathrm{C}$ гипс образуется ангидрит $\left(\mathrm{CaSO}_{4}\right)$, который практически не вступает в соединение с водой. При более высоких температурах $750-800^{\circ} \mathrm{C}$ гипс частично разлагается с образованием извести $\mathrm{CaO}$. При дальнейшем повышении температуры выше $1000{ }^{\circ} \mathrm{C}$ количество извести в гипсе увеличивается.

Традиционная процедура сушки гипсовых стержней и форм включает следующие операции: провяливание на стеллажах после изготовления в течении $1-2$ суток, а затем их сушка в термокамере 56 часов при температуре от 80 до $150{ }^{\circ} \mathrm{C}$. Для интенсификации и сокращения процесса сушки форм и стержней предложено использовать микроволновую печь «Хот-Стрим» ДВ-6-02-6-100.

Сроки затвердевания форм и стержней на основе гипса зависят от ряда факторов: от качества сырья, тонкости помола, условий обжига, температуры окружающей среды, гипса и воды при приготовлении, состава смеси, величины водогипсового соотношения, длительности и условий хранения.

Для приготовления смеси использовали гипс марки Г-10 Н-III ДСТУ Б В.2.7-82-2010, кварцевый песок $1 \mathrm{~K}_{1} \mathrm{O}_{1} 025$ ГОСТ 2138-91, ПАВ, воду.

Гипс и песок смешивают в смесителе в соотношении 2:1 в течении 10 мин до получения однородной сухой массы. Количество воды берется в пропорции на 100 в.ч. смеси 45 в.ч. воды. Температура воды должна быть в пределах 15 - $20{ }^{\circ} \mathrm{C}$. Теплую воду выше $30{ }^{\circ} \mathrm{C}$ применять 
не желательно. Это приводит к быстрой кристаллизации гипса с излишним выделением тепла и увеличением объемного расширения. В воду добавляют ПАВ из расчета 20 грамм на 10 литров воды для улучшения проливаемости и заполняемости формы [11].

Жидкую смесь готовили в специальном миксере, который вращается с частотой $600-$ 800 оборотов/минуту. Перемешивание производили в течении 45 секунд. Время затвердевания такой смеси 11 - 13 минут.

Для исследования процесса сушки были из- готовлены цилиндрические образцы диаметром 70 мм и высотой 110 мм. Были изготовлены четыре партии образцов. Три партии образцов были установлены на стеллаж для провяливания. Первая партия образцов провяливалась в течении 40 часов, вторая - 24 ч, третья - 16 ч. Четвертая партия образцов провяливанию на стеллажах не подвергалась.

Все образцы были взвешены и помещены в микроволновую печь «Хот-Стрим» ДВ-6-02-6100. Сушка проводилась по графику, представленному на рис. 1 .

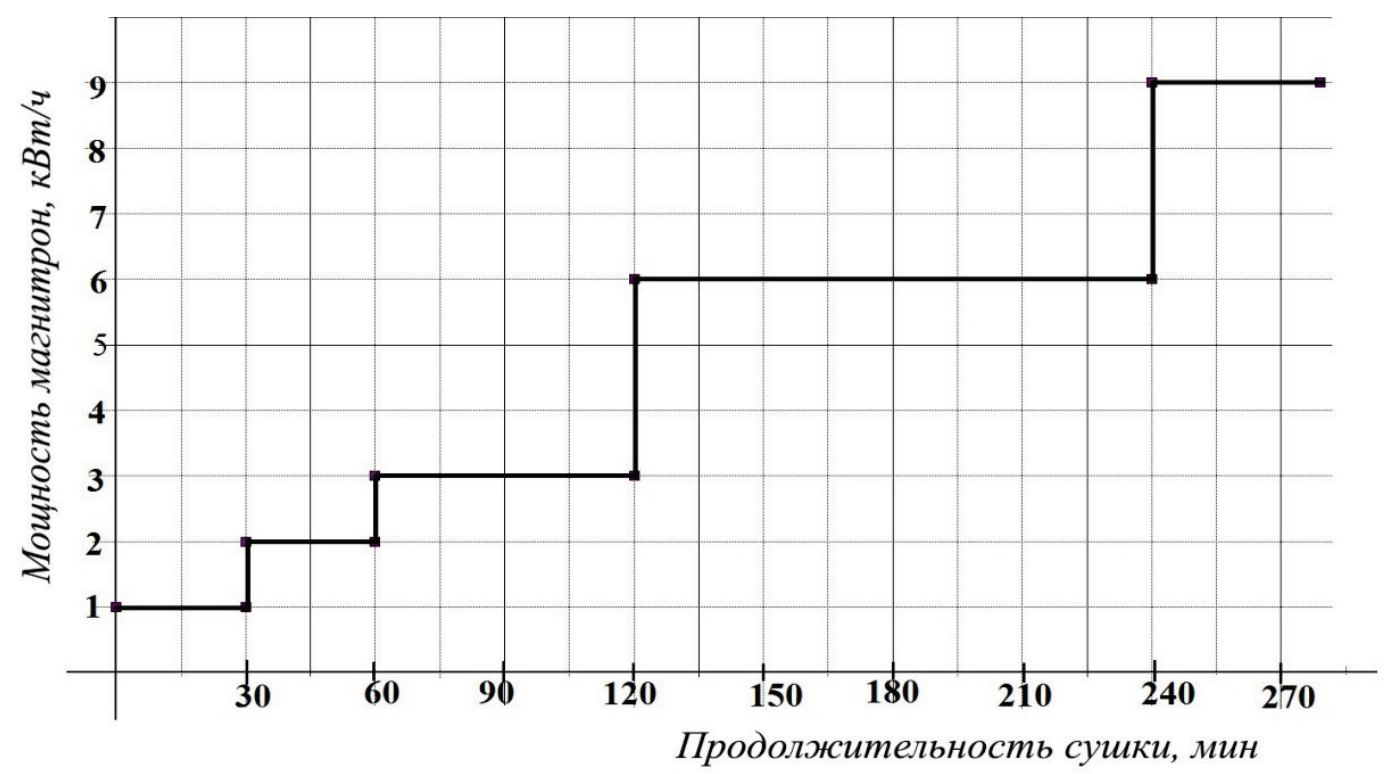

Рис. 1. Схема сушки гипсовых образцов

Сначала включали 1 магнетрон, который работал 30 мин. Мощность одного магнетрона 1 квт/ч. Затем включали второй магнетрон и сушка продолжалась еще 30 мин. Через 1 час были включен третий магнетрон и сушку проводили в течение 60 мин. Через 2 часа после начала интенсивной сушки были включены еще три магнетрона и сушка продолжалась еще 2 час. Затем были включены еще три магнетрона на 30 мин. Общее время сушки 270 мин. Оставшиеся образцы из микроволновой печи были перенесены в тепловой шкаф, где они находились в течении 24 часов при температуре $120^{\circ} \mathrm{C}$ для удаления выступившей влаги с поверхности образцов.

Каждые 15 мин из микроволновой печи извлекались по три образца из каждой партии для взвешивания. Для взвешивания использовали весы лабораторные общего назначения с точность взвешивания 0,01 г.
Влажность образцов $W$ определяли по формуле (1):

$$
W=\frac{Q-Q_{1}}{Q} \cdot 100[\%],
$$

где $Q$ - первоначальная масса образца до сушки, г; $Q_{l}$ - масса образца после сушки, г.

Для каждой партии образцов по результатам экспериментов были построены зависимости потери влаги образцами с течением времени сушки. На рис. 2 представлены зависимости потери веса образцами от времени сушки для каждой партии образцов.

В результате обработки данных в исследуемом интервале было установлено, что потерю веса образцами за время сушки можно описать экспоненциальными уравнениями.

В таблице 1 приведены математические зависимости потери веса образцами за время сушки и величины достоверности аппроксимации $\mathrm{R}^{2}$. 


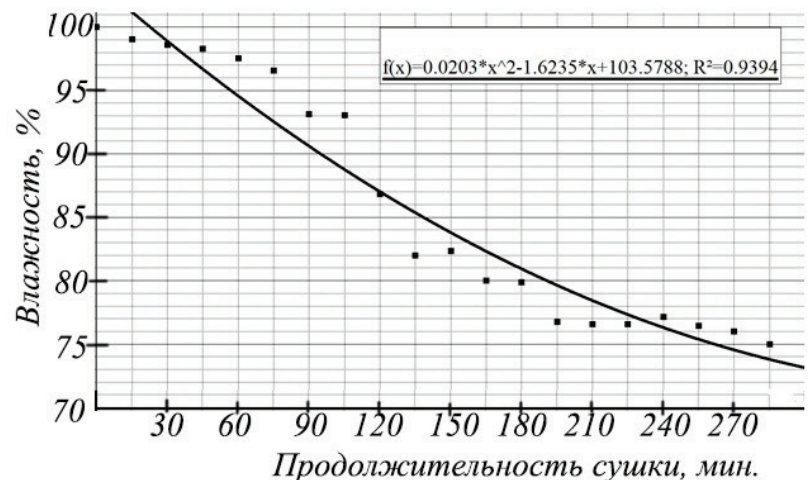

a)

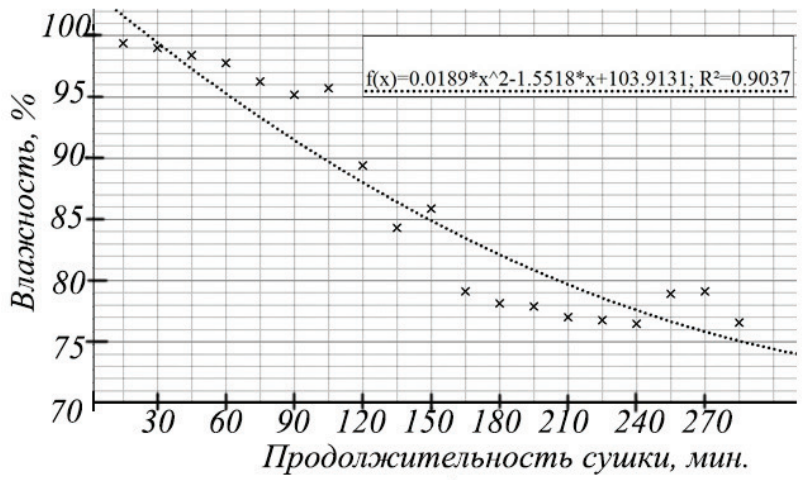

в)

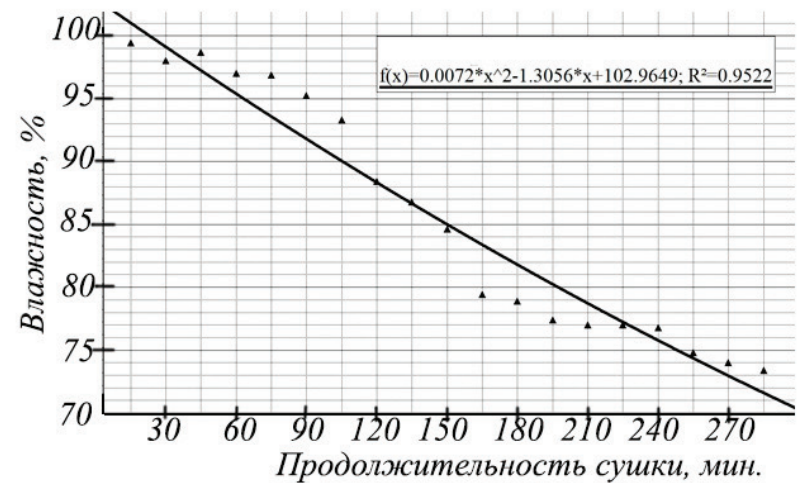

б)

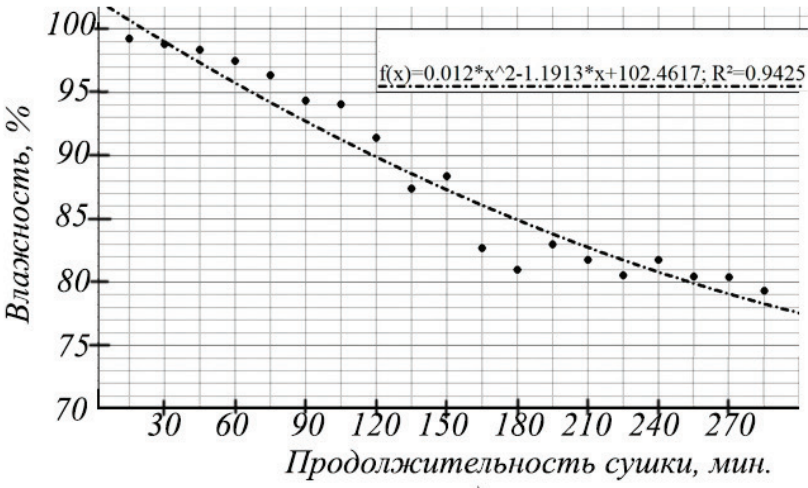

2)

Рис. 2. Зависимость потери веса образцами от времени их сушки: а - для 1 партии образцов, б - для 2 партии образов, в - для 3 партии образцов, г - для 4 партии образцов

Таблица 1. Математические зависимости потери веса образцами за время сушки

\begin{tabular}{|c|c|c|}
\hline Номер партии & Уравнение полиномы & Коэффициент достоверности \\
\hline 1 & $\mathrm{y}=0,0203 \mathrm{x}^{2}-1,6235 \mathrm{x}+103,5788$ & $\mathrm{R}^{2}=0,9394$ \\
\hline 2 & $\mathrm{y}=0,0072 \mathrm{x}^{2}-1,3056 \mathrm{x}+102,9649$ & $\mathrm{R}^{2}=0,9522$ \\
\hline 3 & $\mathrm{y}=0,0189 \mathrm{x}^{2}-1,5518 \mathrm{x}+103,9131$ & $\mathrm{R}^{2}=0,9037$ \\
\hline 4 & $\mathrm{y}=0,012 \mathrm{x}^{2}-1,1913 \mathrm{x}+102,4617$ & $\mathrm{R}^{2}=0,9425$ \\
\hline
\end{tabular}

Опытным путем установлено, что одновременное включение большого количества магнетронов (6-9) приводит к быстрому нагреву форм и стержней, что влечет за собой большой риск их полного разрушения. Кроме того, происходит стремительная потеря влаги в наружных слоях форм и стержней, что значительно увеличивает осыпаемость песка с их поверхности и приводит к образованию засоров в отливках. Прочность форм и стержней при этом резко снижается, нарушается геометрия размеров.

При эксплуатации установки с использованием 1 - 2 магнетронов формы и стержни нагревались очень медленно. Потеря влаги увеличивалась на 5 - $7 \%$ по сравнению с провяливанием на воздухе, время сушки при этом изменилось не существенно.

При режиме работы на 5- 6 магнетронах формы теряют $20-25 \%$ влаги за промежуток времени $3-5$ часов.
Повторная сушка форм и стержней в микроволновой установке приводит к их полному разрушению.

Анализ проведенных исследований показал, что целесообразно использовать комбинированный режим сушки, включающий в себя предварительное провяливание на воздухе, затем плавную сушку в микроволновой установке и дополнительную сушку в тепловом шкафу. Заключительную операцию необходимо производить на протяжении $20-24$ часов для того, чтобы удалить влагу, которая выступает на поверхности форм и стержней при сушке в микроволновой установке. В противном случае при заливке металл «кипит» и в отливках возникают газовые раковины.

При данном режиме сушки формы нагреваются постепенно, только через 2 часа после начала сушки начинается видимое осветление ее поверхности и происходит интенсивная потери влаги, температура поверхности образцов пре- 
вышает $50{ }^{\circ} \mathrm{C}$. После 270 мин такого режима образцы перестают терять влагу, поэтому образцы помещают в термошкаф шкаф для удаления влаги с поверхности образцов. Лучшую чистоту поверхности и меньшую плотность имеют образцы из первой партии.

Экономический эффект при внедрении новой технологии сушки с использованием микроволновой вакуумной установки позволил практически вдвое сократить затраты на электричество. Таким образом заливать метал в гипсовую форму по новой технологии можно уже через сутки после начала сушки, в то время как при стандартном подходе - через трое суток.

Выводы. Значение работы заключается в решении важной научной и технической задачи по сокращению технологического цикла изготовления литейных песчано-гипсовых форм и улучшение их свойств, что будет способствовать более широкому применению данного вида литья в промышленности.

Изучение механизма потери влаги песчаногипсовіми формами позволит:

- вводить в состав смеси только необходимое количество воды, что ведет к снижению брака по газовым раковинам и улучшить качество поверхности отливки;

- определять оптимальное время сушки формы в зависимости от толщины ее стенки и состава формовочной смеси.

Разработаны математические зависимости потери влаги образцами в зависимости от продолжительности сушки, которые можно описать в виде экспоненциальных зависимостей.

Проведены исследования процесса сушки песчаных форм на основе гипса и разработан технологический процесс сушки форм с использованием микроволновой установки, позволивший повысить качество форм и стержней за счет стабилизации их размеров, а также качество сложных алюминиевых отливок.

Предложенный режим сушки позволяет снизить длительность сушки на $40-50 \%$ и тем самым уменьшить затраты на электроэнергию до $50-70 \%$ в зависимости от размеров стержня.

Разработанный технологический процесс сушки показал свою высокую эффективность и был апробирован в производственных условиях НПЦ «Европейские технологии машиностроения», г. Харьков.

\section{Библиографический список}

1. Кукуй Д. М., Скворцов В. А., Эктова В. К. Теория и технология литейного производства. Минск : Дизайн ПРО, 2000. 416 с.
2. Литейные формовочные материалы. Формовочные, стержневые смеси и покрытия : справочник / А. Н. Болдин и др. Москва: Машиностроение, 2006. 507 с.

3. Дорошенко С. П., Авдокушин В. П., Русин К. Формовочные материалы и смеси. Киев : Вища шк., 1990. 415 с.

4. Иванов В. Н. Специальные виды литья/ под ред. В. С. Шуляка. Москва : МГИУ, 2007. $316 \mathrm{c}$.

5. Специальные способы литья : справ. / под ред. В. А. Ефимова. Мщсква : Машиностроение, $1991.436 \mathrm{c}$.

6. Оболенцев Ф. Д. Качество литых поверхностей. Москва : Машгиз, 1965. 284 с.

7. Кестнер О. Е., Бураданьянц В. К. Точное литье цветных сплавов в гипсовые и керамические формы. Москва : Машиностроение, 1973. 287 с.

8. Ясюков В. В., Лысенко Т. В., Волянская К.В. Композиционные отливки с регулируемым поверхностным слоем. Металл и литье Украины. 2016. № 4. С. 36-40.

9. Бураданьянц В. К. Гипсовая оснастка для точного литья. Москва : Машиностроение, 1963. $245 \mathrm{c}$.

10. Мариненко Д. В., Пономаренко О. И., Гримзин И. А. Получение корпусных тонкостенных отливок в гипсовые формы. Матеріали ХII міжнародної науково-практичної конференuіï «Литво-2016» (24-26 травня 2016 р., м. Запоріжжя). Запоріжжя : ЗТПП, 2016. С. 180-181.

11. Гримзин И. А., Мариненко Д. В., Пономаренко О. И. Исследование формовочных смесей на основе гипса в литейном производстве. Матеріали ХІІІ міжнародної науковопрактичної конференщії «Литво-2017» (23-25 травня 2017 р., м. Запоріжжя). Запоріжжя : ЗТПП, 2016. С. 49.

\section{References}

1. Kukui, D. M. Skvortsov, V. A., \& Ektova, V. K. (2000). Teoriia $i$ tekhnologiia liteinogo proizvodstva. Mynsk: Dyzain PRO.

2. Boldyn, A. N. et al. (2006). Liteinye formovochnye materialy. Formovochnye, sterzhnevye smesi i pokrytiia. Moskva : Mashynostroenye.

3. Doroshenko, S. P., Avdokushin, V. P., \& Rusin, K. (1990). Formovochnye materialy $i$ smesi. Kyiv: Vyshcha shk.

4. Ivanov, V. N. (2007). Spetsialnyie vidyi litya. Ed. by V. S. Shulyaka. Moskva: MGIU.

5. Efimov, V. A. (Ed.). (1991). Spetsialnyie sposobyi litya. Moskva: Mashinostroenie.

6. Obolentsev, F. D. (1965). Kachestvo lityih poverhnostey. Moskva: Mashgiz. 
7. Kestner, O. E., \& Buradanyants V. K. (1973). Tochnoe lite tsvetnyih splavov $v$ gipsovyie $i$ keramicheskie formyi. Moskva: Mashinostroenie.

8. Yasyukov, V.V., Lyisenko, T.V., \& Volyanskaya, K.V. (2016). Kompozitsionnyie otlivki s reguliruemyim poverhnostnyim sloem. Metall $i$ lite Ukrainyi, (4) 36-40.

9. Buradanyants, V. K. (1963). Gipsovaya osnastka dlya tochnogo litya. Moskva: Mashinostroenie.

10. Marinenko, D. V., Ponomarenko, O. I., \& Grimzin, I. A. (2016). Poluchenie korpusnyih tonkostennyih otlivok v gipsovyie formyi. Materialy XII mizhnarodnoi naukovo-praktychnoi konferentsii "Lytvo-2016". Zaporizhzhia : ZTPP.

11. Hrymzyn, Y. A., Marynenko, D. V., \& Ponomarenko, O. Y. (2017). Issledovanie formovochnykh smesei na osnove gipsa $\mathrm{v}$ liteinom proizvodstve. Materialy XIII mizhnarodnoi naukovo-praktychnoi konferentsii "Lytvo-2017". Zaporizhzhia : ZTPP.

Мета. Метою роботи є підвищення якості піщано-гіпсових форм за рахунок інтенсифікаиії прочесу їх сушіння, щзо дозволяє скоротити час її проведення $і$ отримувати точні виливки складної форми необхідної якості.

Методика. Дослідження проводиласи на иіліндричних зразках з піщаної суміші на основі zincy в якості в'яжучого матеріалу. Зразки піддавалися сушінню в мікрохвильовій печі «Хот-Стрім» ДВ-6-02-6-100. Зважуванням визначалося втрата вологості зразками в залежності від часу сушіння зразків.

Результати. Вивчено процес втрати вологи зразками і розроблено математичні залежності втрати вологи від тривалості сушіння. Визначено необхідну кількість води, щзо дозволяє знизити брак стосовно газових раковин $i$ поліпшити якість поверхні виливки. Економічний ефект при впровадженні нової технології сушіння з використанням мікрохвильової вакуумної установки дозволило практично вдвічі скоротити витрати на електрику.

Наукова новизна. Вперше науковообтрунтовано режим роботи мікрохвильової печі для сушки песчаногіпсових форм і стрижнів. Розроблено математичні залежсності втрати вологи зразками в залежності від тривалості сушіння, що можна описати у вигляді експонениійних залежностей.

Практична цінність. Розроблено технологічний прочес сушіння форм з використанням мікрохвильової установки, щьо дозволило підвищитти якість форм і стрижснів за рахунок стабілізаиії їх розмірів, а також якість складних алюмінісвих виливків за рахунок зниження браку по газовим раковин.

Запропоновано режим сушіння, що дозволяє знизити тривалість сушіння на 40...50\% $i$ тим самим зменшити витрати на електроенергію до 50.. $70 \%$ в залежності від розмірів стрижнів.

Ключові слова: формувальні суміші на основі гіпсу, сушка, мікрохвильова установка, алюмінієві виливки.

Purpose. The goal of this work is to improve quality sandy-gypsum forms due to the intensification process of their drying, allowing to reduce its time and receive the exact moulding with complex shape and the required quality.

Methods. Research was carried out on cylindrical samples made of gypsum-based sandy mixture used as a binder.

Samples were dried in the microwave oven "Hot-stream" DV-6-02-6-100. Moisture loss by samples depending on the time model was dried was measured by weighing.

Results. The process of moisture loss by samples were studied and developed mathematical dependencies between moisture loss and drying time.

Necessary amounts of water are defined, which allows to reduce the number of defects on gas sinks and improve casting surface quality. Economic effect when introducing new drying technology using microwave vacuum installation allowed to reduce electricity costs almost by half.

Originality. For the first time scientificallygrounded operating mode of microwave oven for drying sandy-gypsum forms and rods. Developed mathematical dependencies between moisture loss and drying time, so that they can be described as exponential dependencies.

Practical implications. Developed a technological drying process of forms using microwave installation, that allowed to improve the quality of forms and rods due to stabilization of their sizes, and the quality of complex aluminum castings due to reducing the number of defects on gas sinks.

The suggested drying mode allows to reduce the drying time by $40 \ldots 50 \%$ and thereby reduce electricity costs up to $50 \ldots 70 \%$ depending on the size of the rod.

Key words: gypsum-based molding compounds, drying, microwave installation, aluminum castings.

Рукопис надійщов 01.11.2019 